\title{
Una Barbería 'Nuyorrican': Género, Política y Mercado en Una Instalación De Pepón Osorio'
}

\author{
Uma barbaria Nuyorrican: \\ Genero política e mercado em um intalação de Pepón Osorio \\ Jeffrey Cedeño Mark* \\ Pontificia Universidad Javeriana - Bogotá, Colômbia e-mail: jcedeno@javeriana.edu.co
}

RESUMEN: Al subvertir los espacios que fundan y modelan los valores del machismo en la comunidad latina de la Costa Este de los Estados Unidos, la instalación En la barbería no se llora (1994) de Pepón Osorio convoca una inquietante hibridación cultural ocupada en evaluar las contradicciones y ambivalencias del machismo y las categorías de género dentro de la experiencia migrante "nuyorrican". Se trata de una política de representación kitsch, femenina y alegórica capaz de interrogar, sin duda, el estado del arte en su diálogo con la política y el mercado a la hora de repensar la construcción identitaria de los grupos minoritarios dentro de la metrópolis estadounidense. A partir de este complejo trazado, el artículo examina las contradicciones irresueltas que exhiben los objetos estéticos y culturales en su funcionamiento social, en sus articulaciones y cruces locales y globales, sin olvidar sus delimitaciones recíprocas con las relaciones del poder cultural -de dominación y subordinación- desde las variadas esferas públicas en juego.

PALABRAS-CLAVE: Gênero; política; instalação; En la barbería no se llora.

RESUMO: Ao subverter os espaços que fundam e modelan os valores do machismo e da comunidade latina da Costa Este dos Estados Unidos, a instalação En la barbería no se llora (1994) de Pepón Osorio convoca uma inquietante hibridação cultural focada em avaliar as contradições e ambivalencias do machismo e das categorías de gênero dentro da experiencia migrante "nuyorrican". Trata-se de uma política de representação kitsch, feminina e alegórica capaz de interrogar, sem dúvida, o estado da arte em seu diálogo com a política e o mercado na hora de repensar a construção indentitária dos grupos minoritários dentro da metrópolis estadunidense. A partir deste complexo traçado, o artigo examina as contradições irresolutas que exibem os objetos estéticos e culturais em seu funcionamento Social, em suas articulações e fluxos locais e globais, sem esquecer suas delimitações recíprocas com as relações do poder cultural - de dominação e subordinação - das variadas esferas públicas em jogo.

\footnotetext{
1 Una versión anterior de este ensayo se publicó en el Arizona Journal of Hispanic Cultural Studies, Vol XII, 2008, bajo el título "Lágrimas en Connecticut: género, política y mercado a partir de una instalación de Pepón Osorio".
}

Volume 17

Número 38 


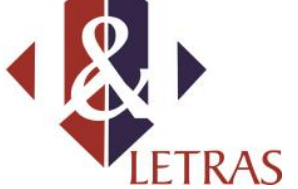

PALAVRAS-CHAVE: Gênero; política; instalação; En la barbería no se llora.

\section{LOS DÉDALOS DEL GÉNERO TRAS LA POLÍTICA DEL ESPACIO}

Aquélla mañana de 1994 la 481 Park Street del barrio Frog Hollow en Hartford, Connecticut, no era la misma. La diferencia encontraba su lugar en una barbería que, luego de varios meses enfrentando el más completo de los abandonos, abría nuevamente sus puertas; pero en esta ocasión, y como quien resurge de sus cenizas, su nombre no podía ser menos que otro: En la barbería no se llora. Al colocar un pie más allá del umbral nos captura un escenario colmado de ornamentos brillantes y lustrosos, colores vivos y sugerentes imágenes: proliferan figurillas de santos y de niños en su primera comunión, ángeles negros y blancos, afiladas cuchillas, flores plásticas, sandalias, linternas, fichas de dominó, hojas de plástico, soldaditos de juguete, metras, encajes, lupas, condones, barajas, peines de afro, cucharillas, placas policiales estadounidenses, carritos. La silla de afeitar, colmada de tales miniaturas, se encuentra tapizada con una tela roja que lleva grabada en serigrafía la atlética figura de un cuerpo masculino. Abundantes trozos de cabello negro rizado cubren los alrededores de la silla: sólo un mechón rubio lacio establece el contraste. Los monitores de video, situados en las esquinas de la barbería, transmiten las imágenes — sin audio - de hombres latinos llorando dolorosamente o cumpliendo rutinas de ejercicio muscular en un gimnasio. Las paredes exhiben un florido papel tapiz y en el techo podemos encontrar imágenes en acuarela de espermatozoides gigantes. No podían faltar la bandera puertorriqueña y los radiofónicos acordes de música latina. ${ }^{2}$

Me encontraba dentro de la instalación En la barbería no se llora (1994), del artista nuyorriqueño Pepón Osorio, artífice de tal reapertura. Se entiende: la barbería constituye un espacio recortado sobre los valores "naturales" de la masculinidad y, por ello, no puede menos que funcionar e intervenir en tal dirección. ${ }^{3}$ Resulta evidente que la barbería de Park

\footnotetext{
${ }^{2}$ Mi segundo encuentro con la instalación de Pepón Osorio se produciría cuatro años después, en 1998, pero ya no en otra calle de un barrio latino estadounidense, sino en el Museo de Artes Visuales Alejandro Otero (MAVAO), en Caracas. En la barbería no se llora forma parte de la Colección permanente del Museo de Arte de Puerto Rico, en San Juan, donde se puede ver en la actualidad.

${ }^{3}$ En América Latina, la barbería se distancia de la peluquería en la medida en que ésta última se encuentra culturalmente codificada como un lugar femenino y, también, homosexual. Por lo tanto, doble ruptura del género masculino desde el esencialismo heterosexual. En Bogotá, por ejemplo, la pérdida de espacio simbólico y comercial de las barberías ha producido una interesante dinámica de hibridación y reconversión Volume 17

Número 38
} 


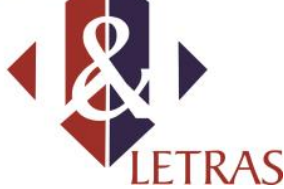

Street presenta los signos naturalizados del sujeto masculino -carritos, cuchillas, canicas- desde una imaginería kitsch, figurativa y sentimental —doméstica y femenina, por lo demás, como bien lo ejemplifican, las flores, los colores lustrosos, los encajesocupada en preservar el origen identitario (y nacional) de muchos hogares populares latino/americanos (en una abierta actualización del horror vacui); al tiempo que escenifica los pliegues de una memoria afectiva al entrecruzar experiencias históricas dispares femenino/masculino, pasado/presente, metrópolis/colonia- y cuyas significaciones in/forman las ambigüedades y contradicciones que intervienen, en cierta medida, en el desplazamiento identitario que convoca la migrancia latina en los Estados Unidos. ${ }^{4}$

Una vez invadido por la plétora visual de la barbería, por su intenso dialogismo, pude advertir los juegos referenciales de una poética espacial capaz de fracturar o suspender la narrativa que me auguraba (y aseguraba) la literalidad de un "lugar" anclado en uno de los valores del machismo latino/americano: aquél donde, precisamente, el llorar es una prohibición. El ilusionismo referencial - trompe-l'oeil- que sustenta la barbería funciona como una objetivación simbólica de la norma heterosexual en tanto discurso naturalizado en los múltiples tránsitos y niveles de la realidad, al tiempo que exhibe su irreductible artificio, su propia re-presentación: el artificio consume a la barbería y a sus ficciones de identidad puesto que fractura deliberadamente cualquier tipo de continuidad naturalizada entre el género, el sexo y el espacio. Contrario a sus intensiones, el trompel'oeil nos dice que la hegemonía heterosexual no posee la realidad, mucho menos su exclusiva, pura y generalizada representación y, de este modo, deja abierta la pregunta sobre la noción de lo real desde sus históricas formaciones discursivas, el género entre ellas.

Pero la 481 de la Park Street no logra someterse a la domesticación espaciotemporal que ejerce su imperativa sentencia en tanto categoría nominativa e identitaria. No

cultural, tal como sugerentemente lo afirma Julia Londoño Bozzi: "Ante el peligro de desaparecer por la clientela que cada vez más escasa que prefiere al barbero que a su Prestobarba portátil, las barberías han mutado en salones de belleza donde además de política, también se discute de reinas, y donde hay cada vez menos periódicos que revistas Vanidades, en manos de la clientela" $(2002,28)$. De igual modo, conviene apuntar que, aún hoy, muchos hombres latinoamericanos, tanto de áreas urbanas como rurales, se resisten a colocar un pie en una peluquería.

${ }^{4}$ Dice Svetlana Boym que, "In contrast to the utopian images of intimacy as transparency, authenticity, and ultimate belonging, diasporic intimacy is dystopian by definition: it is rooted in the suspicion of a single home [...] Diasporic intimacy is not limited to the private sphere but reflects collective frameworks of memory that encapsulates even the most personal of dreams. It is haunted by images of home and homeland, yet it also discloses some of furtive pleasures of exile" $(1998,500)$.

Volume 17

Número 38 
sólo podemos decir, con la instalación, que en la barbería sí se llora; también, y sin ningún tipo de tapujos, se puede llorar: ante mis ojos desfilan las imágenes de video — sin audiode hombres llorando en la barbería; silenciados, exhiben públicamente su dolor. No logro saber por qué o por quién lloran; lo importante, siguiendo a Vilém Flusser, es la significación política y cultural que adquiere tal gesto en la medida en que se expresa simbólicamente frente a los otros (1994 14-15), en una clara fractura de los fundamentos constitutivos del machismo.

Creo que la instalación de Osorio si bien examina la construcción de la masculinidad en la cultura latino/americana, se erige como un espacio estético, político y cultural altamente contradictorio desde el justo momento en que delimita, quiera o no, con la espectacularización de las identidades subalternas que agencian en buena medida las fuerzas productivas del mercado a escala global. Colocar el pie en la identidad es, de algún modo, pisar el maleable terreno del mercado y justo en tales arenas la instalación de Osorio no puede menos que jugar una definición estética, cultural y política capaz de evidenciar el estado actual del arte en relación con la política y el mercado. Y he aquí, entonces, el centro de mi reflexión en las próximas líneas.

Problematizar los territorios que sostienen e inscriben la gramática del machismo latino/americano significa, en principio, problematizar la "ilusión de sujeto" que lo habita y lo legitima; problematizar, en suma, las fábulas de identidad y los autorreferenciales aparatos de producción de discursos y prácticas sociales que intentan "naturalizar" el espacio apuntando a lo "natural" del género desde una división heterosexual. ${ }^{5}$ En este sentido, la significación natural (normativa) del género se produce "dentro de la órbita de la obligación de repetir"; si consideramos que la capacidad de acción emerge, preciso, en la posibilidad de variar las formulaciones iterativas (Butler 2001 a 176). Asistimos entonces, con la instalación de Park Street, a una estrategia de des-identificación dentro de un juego de las representaciones culturales: la instalación disemina alegóricamente los soportes naturalizados del macho latino dentro de una serialidad doméstica -encajes, flores, recordatorios, fotografías - y, de este modo, erige una abierta (con)fusión de campos simbólicos restringidos —masculino/ femenino, público/ privado, racional/ sentimental, doméstico/ laboral一, todo lo cual subvierte la retórica que los mismos escenifican para

\footnotetext{
5 Tal planteamiento constituye una "desviación" de los argumentos desarrollados por Graciela Montaldo (1999) en relación con lo "natural" del territorio latinoamericano en el siglo XIX.
}

Volume 17

Número 38 
establecer las reglas "naturales" de su propio consumo en la formación jerárquica y heterosexual de subjetividades individuales y colectivas, como bien lo ejemplifica toda barbería. Surge al punto una apertura en las posibilidades de acción y construcción del sujeto masculino, capaz de interrogar el espacio de/ para la representación de la identidad cultural - y del machismo latino en particular- desde la representación misma en tanto práctica y estrategia significante central en la formación de los discursos productores del género y en los desplazamientos culturales que históricamente inciden en la reconstitución de todo tipo de identidades: las migraciones verbigracia.

La interpelación que inscribe la barbería de la Park Street alcanza al cuerpo como uno de los principios fundamentales de la masculinidad machista: el sujeto masculino en exhibición devela, sí, un multiplicado regodeo sobre el cuerpo capaz de hacer visible una economía de género confinada al ocultamiento por la hegemonía heterosexual: la artificialidad, la espectacularidad y el narcisismo; la sensibilidad y la estética como formas y prácticas de construcción del sujeto masculino y del macho latino en particular. Tiene razón Coco Fusco cuando dice que "Osorio le pide a sus espectadores abiertamente que reconozcan los aspectos tan espectaculares y narcisistas de la identidad masculina, resaltando una contradicción interna del machismo latino que implica que para verse macho uno debe maquillarse, como lo hace una mujer" (1998 iii-iv). El cuerpo atlético grabado en serigrafía o las imágenes de jóvenes realizando ejercicio muscular en un gimnasio que exhiben los monitores de la instalación nos dicen cómo el cuerpo se torna significante de un muchas veces doloroso trabajo físico que intenta sostenidamente marcarlo y trazarlo para alcanzar su forma "natural". Se trata de la búsqueda de un límite primigenio capaz de acentuar su diferencia con respecto al cuerpo femenino para, de este modo, corporeizar y exhibir, entre otras cosas, la transparencia esencial de la masculinidad, afianzar la normatividad heterosexual, $\mathrm{y}$, también, palpar su modélica escenificación. Una escenificación que hace visible un desplazamiento en el orden de la constitución y representación del sujeto masculino en la medida en que logra nutrirse de las resignificaciones estéticas (y políticas) que opera sobre el cuerpo la mercadotecnia globalizada en la inscripción de nuevos hábitos de consumo - la salud, la higiene y el cuidado corporal, la cosmética masculina, el consumismo light, la cirugía plástica一. Todo lo anterior, no obstante, reinscribe los valores tradicionales del machismo en América Latina al trazar un regodeo sobre-identitario y narcisista —irónicamente efectista, en sí Volume 17

Número 38 


\section{GÉNERO, POLÍTICA Y MERCADO}

La instalación de Osorio, en efecto, retorna al orden de lo social por medio de la búsqueda de una nueva significación del género capaz de convocar, inevitablemente, otras formas de socialización —desde un vitalismo relacional, desde la producción y reproducción social del espacio y de sus codificaciones normativas, sin olvidar las reglas de construcción del género masculino- cuyo carácter político se trama, preciso, en las concepciones populares - las más de las veces esencialistas y conservadoras- del cuerpo, la masculinidad y la feminidad. Se entiende: los procesos de democratización se recortan sobre la dimensión de lo popular y, por ello mismo, habría que preguntarse cuáles son las refuncionalizaciones políticas que agencian diversas fuerzas sociales -el mercado, el Estado, la sociedad civil- sobre tal esfera. En todo caso, y visto desde la instalación que me ocupa, lo kitsch y lo (neo)barroco constituyen no sólo un campo de reconocimiento para los sectores populares, sino también formas estéticas ocupadas en negociar reconversiones culturales dentro de la comunidad boricua, latino/americana in extenso. En este sentido, la instalación se erige como una autoridad capaz no sólo de socializar el arte, sino también discutir experiencias comunes de subordinación - genérica, comunitaria, colonial一 dentro de la reconversión histórica que convocan en buena medida los procesos migratorios y, justo aquí, la barbería hace contrapunto con un mercado global que no duda en flexionar significados y valores sobre tales experiencias inscribiendo muchas veces un franco desalojo de la historia y la identidad.

Pero también la instalación de Osorio, quiera o no, retorna a las formalizaciones del mercado desde el justo momento en que la barbería coloca en la escena pública una reivindicación estética y política del estereotipo y del kitsch como legítima formación cultural e identitaria latino/americana. Lo anterior abre un contradictorio y riesgoso diálogo con las políticas neoliberales cuyas proyecciones avanzadas requieren apropiarse -muchas veces indiscriminadamente- de los contenidos culturales — las formaciones de género, por Volume 17

Número 38 
ejemplo-, de allí, se entiende, la estetización generalizada del mundo que hace parte de sí la revalorización fetichista de una periferia multicultural. La expansión e intensificación de la forma mercancía como manifestación cultural no puede borrar las diferencias entre los objetos y las prácticas culturales en la medida en que participan y responden a sujetos, discursos e instituciones muchas veces disímiles, informando, no lo olvidemos, relaciones sociales específicas. Es claro que la transformación en mercancía puede constituirse como una estrategia de intervención simbólica efectiva para los grupos minoritarios, si consideramos que el mercado no logra reducirse a formas de alienación y, más allá, puede consolidar formaciones comunitarias de diversa índole; no obstante el peligro surge cuando los modos de tal intervención no trascienden las estrategias y tropos que ofrecen y sustentan ávidamente las fuerzas productivas del mercado a escala global, lo cual concluye en una explícita mímesis de alcance político dudoso. Una mímesis que, conviene decirlo, no se agota en los formatos y sus continuas innovaciones, pues las políticas mercantiles bien saben que éstos carecen de valor si no adelantan una franca apropiación de los contenidos culturales, cualquiera que sean.

Los procesos de hibridación cultural encuentran una materialidad privilegiada en los entrecruzamientos resignificantes de lo local y lo global desde diferentes registros y contextos sociales de estructuración e intervención —como bien lo ejemplifica no sólo la producción artística de Osorio, sino también la de muchos artistas latinos en Estados Unidos-; sin embargo, sus inscripciones políticamente significativas no pueden obviar la densidad de las estrategias de formación de un mercado global cuya intensificación y expansión abre estrategias que se nutren y mimetizan incluso con lo relacional, lo híbrido y lo "sub/alterno". 6 Tal "concordancia" borra, al menos en un principio, fronteras simbólicas instituidas y, por lo tanto, mina el campo de las políticas de representación identitarias en sus varios niveles, si consideramos que lo subversivo exhibe, hoy, un claro valor de mercado. Tanto la subversión de las instituidas normas de género como los límites de las políticas de asimilación cultural metropolitana que escenifica la barbería, podrían concluir en un acto fugaz e intrascendente - performance que se devora a sí misma- capaz de

\footnotetext{
${ }^{6}$ Tal como lo expresa Coco Fusco, "El kitsch es la única expresión cultural bajo la que es aceptada la cultura latina en Nueva York y en los Estados Unidos" (Subirats, 2001, 104, las cursivas son mías). En este sentido, la colorida profusión neobarroca de la barbería de Osorio traza distancias con esa otra estética propia del mercado global, ligera y transparente, que prescinde de toda ubicación geográfica y connotación local: el minimalismo de las tiendas de los shopping-center.
}

Volume 17

Número 38 
propiciar una reinversión en la dinámica de las apropiaciones y resignificaciones culturales que da como resultante la incorporación de manifestaciones marginales y transgresoras por parte de ese cuestionado centro hegemónico.

¿Cómo armar, entonces, una política de representación estética desde una vertiente híbrida, migrante y bilingüe, marcada por la subalternización en la cultura estadounidense? ¿Cómo superar tal prueba sin capitular frente a las políticas anestesiantes de un voraz — por diversificado- mercado global?, ¿Cómo diseñar e inscribir, a partir de una manifestación cultural, una intervención política efectiva y transformadora? Tales interrogantes no son nuevas, ciertamente; pero su constante (re)formulación y persistencia no sólo ponen a prueba el estatuto del arte, también exhiben los pliegues de un orden cultural que no logra consumirse en la práctica — social in extenso- de la "resignificación". Coincido, en este sentido, con Nancy Fraser (1997) y Judith Butler (2001b) cuando argumentan que la "resignificación" no resulta suficiente para erigir una intervención política puesto que no garantiza, por sí misma, consecuencias éticas saludables en aras de una apropiación derivada de una teoría radical democrática. La resignificación convoca prácticas diferenciadas y, por lo tanto, sus usos no pueden ser menos que contrastantes al servicio de cualquier intervención con fines políticos. La resignificación kitsch, paródica y alegórica del macho latino que convoca En la barbería no se llora fractura prácticas, normas y relaciones sociales de género dentro de la tradición latino/americana desde una performance cuya efectividad tal vez describa, fundamentalmente, y en su migrante multiplicidad, el sujeto cultural que requiere el capitalismo avanzado.

No resulta conveniente obviar que la diferencia cultural constituye, en principio, una categoría moderna y esta carga de significación histórica delimita —en forma equivalente- con las políticas de identidad ocupadas en democratizar la redistribución económica y el reconocimiento cultural. De allí la centralidad de las representaciones culturales dentro del campo de posibilidades sociales y económicas que articulan las intervenciones políticas. Lo anterior nos ofrece reversos inquietantes: sin perder de vista el travestismo que destila la instalación de Osorio, recordemos que el travesti, por ejemplo, se ha convertido, como apunta Jean Franco, en una "metáfora de la marginalidad" capaz de reforzar la estructura de poder existente y reintroducir ya no un diálogo o una borradura de géneros normativos, sino, preciso, "un placer masculino que parece derivar de la ambigüedad de la representación travesti como a una mujer y por tanto como abyecta" Volume 17 Número 38 
(1996 126). Es claro que, al menos en su diálogo con los estereotipos culturales metropolitanos, la instalación de Osorio encuentra, en cierta medida, límites a sus intervenciones/ desestabilizaciones políticas tras el reconocimiento cultural, todo lo cual pone a prueba, desde su ejemplarizante singularidad, el sentido del arte, del género y la cultura en su diálogo con lo político y lo mercantil.

Sin embargo resulta difícil establecer contextos pertinentes a la hora de maniobrar intervenciones políticas capaces de modificar los procesos sociales y culturales en curso: las formas efectivas de organización y participación política no están claras, tampoco resultan nítidas la miríada de subjetividades sociales y sus procesos de formación identitaria. Aún no es del todo evidente si las políticas de identidad —en sus diversas formulaciones teóricas y prácticas - inscriben una articulación política efectiva dentro del conglomerado social estadounidense. Las manifestaciones estéticas que estructuran y legitiman tal política se recortan, en estricto sentido, sobre un campo minado pues se trata de medios y fines que bien podrían conducir a la despolitización, en un meridiano desalojo de la identidad de grupo que se pretende reivindicar. Las políticas de identidad bien podrían materializar un fracaso sin más o, por ejemplo, responder a soluciones económicas ocupadas en desplazar o subsumir la autonomía de la agencia política: surge entonces la persistente pregunta por el lugar y la definición del arte y del género frente a tales resultados.

En la barbería no se llora desestabiliza las diferencias de género y las identidades que las acompañan, pero también exhibe la exigencia política de una identidad que trata de construirse en medio de las relaciones de poder colonial: la nuyorrican. Esta articulación no resulta fácil, pues bordea los contornos de un mercado global francamente ambiguo en su cruce con lo político. Considerando todo lo anterior, resulta necesario, tan sólo en un primer estadio, atender teórica y críticamente las contradicciones irresueltas que exhiben los objetos estéticos y culturales en su funcionamiento social, en sus articulaciones y cruces locales y globales, sin olvidar sus delimitaciones recíprocas con las relaciones del poder cultural —de dominación y subordinación- desde las variadas esferas públicas en juego - las esferas públicas de los centros de poder, las esferas contra-públicas y las esferas públicas informales de la vida cotidiana, como diría Nancy Fraser (1997)—. En tales contradicciones se desteje el espacio de la cultura en el presente entresiglo, lo cual no anula, a pesar de las contingencias sociales mencionadas arriba, y como bien lo dice Volume 17

Número 38 


\section{REFERÊNCIAS}

BENÍTEZ, Marimar. "Neurotics Imperatives: Contemporary Art from Puerto Rico". Art Journal, Vol. 57, No. 4 (Winter 1998): 74-85.

BOURDIEU, Pierre. La dominación masculina. Barcelona: Anagrama, 1999.

BOYM, Svetlana. “On Diasporic Intimacy: Ilya Kabakov's Installations and Inmigrant Homes”. Critical Inquiry 24 (Winter 1998): 498-525.

BUTLER, Judith. El género en disputa. México: Paidós/ UNAM, 2001a.

"La cuestión de la transformación social". En Mujeres y transformaciones sociales,

editado por Elisabeth Beck-Gernsheim. Barcelona: Roure Editorial, 2001b: 98-102.

Mecanismos psíquicos del poder. Teorías sobre la sujeción. Madrid: Cátedra, 2001c Cuerpos que importan. Barcelona: Paidós, 2002.

CRUZ-MALAVÉ, Arnaldo. "The Oxymoron of Sexual Sovereignty: Some Puerto Rican Literary Reflections". Centro Journal, Año/ vol. XIX, No. 001, 50-73.

DE CERTEAU, Michel. Culture in the Plural. Minneapolis: The University of Minesotta Press, 1997.

DERRIDA, Jacques. “Conversación con Jacques Derrida”. Revista de Crítica Cultural 12 (Julio 1996): 14-21.

DEUTSCHE, Rosalyn. Evictions. Art and Spatial Politics. Cambridge: The MIT Press, 1998.

DYER, Richard. The Matter of Images. London and New York: Routledge, 1993.

FLORES, Juan. Divided Borders. Essays on Puerto Rican Identity. Houston: Arte Público, 1993.

"Pan-latino/Trans-latino: los puertorriqueños en el Nuevo New York". Estudios 14/ 15 (Julio 1999-Junio 2000): 51-80.

From Bomba to Hip Hop: Puerto Rican Culture and Latino Identity. New York: Columbia University Press, 2000.

FLUSSER, Vilém. Los gestos. Fenomenología y comunicación. Barcelona: Herder, 1994.

FRANCO, Jean. Marcar diferencias, cruzar fronteras. Santiago: Cuarto Propio, 1996.

FRASER, Nancy. Justice Interruptus. Londres y New York: Routledge, 1997.

FULLER, Norma. "Reflexiones sobre el machismo en América Latina". En Masculinidades y equidad de género en América Latina, editado por Teresa Valdés y José Olavaria. Santiago: FLACSO/ UNFPA, 1998: 258-266.

FUSCO, Coco. English is Broken Here. New York: The New Press, 1995.

"En la barbería no se llora" (Catálogo). Caracas: Museo Alejandro Otero, 1998.

CANCLINI, Néstor García. Culturas híbridas. México: Grijalbo, 1989.

"Entrar y salir de la hibridación". Revista de crítica literaria latinoamericana 50 (Segundo semestre 1999a): 53-57.

La globalización imaginada. Buenos Aires: Paidós, 1999b.

GONZÁLEZ, Beatriz Stephan. "Héroes nacionales, estado viril y sensibilidades homoeróticas." Estudios 12 (Julio-Diciembre 1998): 83-122.

Volume 17

Número 38 
GUTMANN, Matthew C. "El machismo". En Masculinidades y equidad de género en América Latina, editado por Teresa Valdés y José Olavaria. Santiago: FLACSO/ UNFPA, 1998: 238-257.

HALL, Stuart (ed.) "The Spectacle of the Other". En Cultural Representations and Signifying Practices. London: Sage, 1997: 1-120.

INDYCH, Anna. “Nuyorican Baroque: Pepón Osorio’s Chucherías”. Art Journal, Vol. 60, No. 1 (Spring 2001): 72-83.

JAMESON, Fredric. El postmodernismo y lo visual. Valencia: Ediciones Episteme, Vol. 153, 1997.

JUHÁSZ, Emeshe Mininberg. "Puerto Rico y las fronteras de la identidad nacional". Revista Venezolana de Economía y Ciencias Sociales 7 (3) (Septiembre-Diciembre 2001): 197-217.

LECHNER, Norbert. “Cultura política y gobernabilidad democrática”. Leviatán 68 (Verano 1997): 75-83.

LONDOÑO, Julia Bozzi. "La barbería tradicional en Bogotá: Sobrevivimos hasta los hippies". Directo Bogotá 1 (Febrero 2001): 25-28.

LÓPEZ, Ana Tiffany. "Imaging Community: Video in the Installation Work of Pepón Osorio". Art Journal, Vol. 54, No. 4, Video Art (Winter 1995): 58-64.

MASIELLO, Francine. "Género, vestido y mercado: el comercio de la ciudadanía en América Latina”. Estudios 9 (Julio-Diciembre 1996): 91-106.

"La insoportable levedad de la historia: los relatos Bestseller de nuestro tiempo".

Cuadernos de Literatura 8 (15) (Enero-Junio 2002): 59-75.

MOLLOY, Sylvia. "La política de la pose". En Las culturas de fin de siglo en América Latina, compilado por Josefina Ludmer. Rosario: Beatriz Viterbo Editora, 1994: 129-138.

MONTALDO, Graciela. Ficciones culturales y fábulas de identidad en América Latina. Rosario: Beatriz Viterbo Editora, 1997.

MOSQUERA, Gerardo. "Allen-Own/Own-Alien: Globalization and Cultural Difference". Boundary 2 29: 3, 2002: 167-177.

NEGRÓN-MUNTANER, Frances y Ramón Grosfoguel, editores. Puerto Rican Jam: Essays on Culture and Politics. Minneapolis: University of Minnesota Press, 1997.

OLALQUIAGA, Celeste. Megalópolis. Caracas: Monte Ávila Editores, 1993.

OLEA, Raquel. "Libertad de arte y otros imaginarios". La época, Santiago de Chile, 19 de agosto, 1994.

RICHARD, Nelly. Masculino/ femenino. Prácticas de la diferencia y cultura democrática. Santiago: Franciso Zegers Editor, 1993.

ROSMAN, Silvia. Dislocaciones culturales. Nación, sujeto y comunidad en América Latina. Rosario: Beatriz Viterbo Editora, 2003.

SARDUY, Severo. La simulación. Caracas: Monte Ávila Editores, 1982.

SCHOR, Naomi. Reading in Detail: Aesthetics and the Feminine. Londres: Metheun, 1987.

Stewart, Susan. On Longing. Narratives of the Miniature, the Gigantic, the Sourvenir, the Collection. New York y Londres: Duke University Press, 1993.

SUBIRATS, Eduardo. "Coco Fusco: Entre Vista”. Debats 74: 104-106 (Otoño 2001).

WILLIAMS, Raymond. Marxismo y literatura. Barcelona: Península, 1997.

YÚDICE, George. El recurso de la cultura. Barcelona: Gedisa, 2003. 


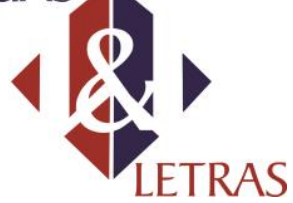

e-ISSN: 1981-4755

DOI: $10.5935 / 1981-4755.20160004$

Figuras 1, 2 y 3, "En la barbería no se llora", Pepón Osorio.
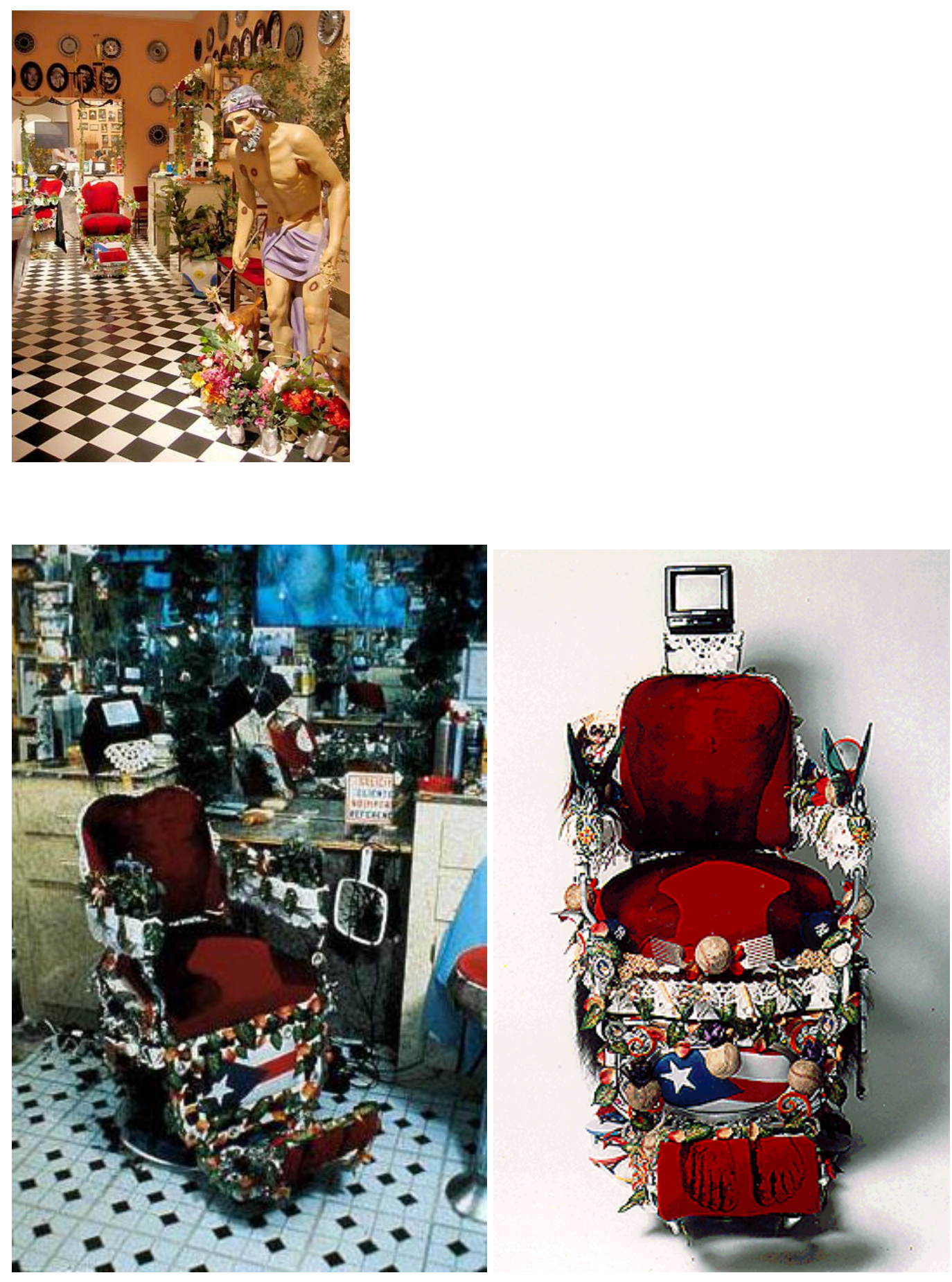

Data de recebimento: 28/11/2016

Data de aprovação: 28/11/2016 